\title{
AUTOMAÇÃO DE UNIDADES DE INFORMAÇÃO ARQUIVÍSTICA: O MODELO ALTERNATIVO DO SOFTWARE LIVRE
}

\author{
João Tiago Jesus Santos \\ Lídia Maria Batista Brandão Toutain
}

\begin{abstract}
Resumo
O artigo estabelece uma discussão no âmbito dos softwares de gestão arquivística de documentos. Estudos anteriores revelam um considerável leque de produtos dessa categoria; contudo, o universo contemplado nessas análises é predominantemente de software proprietário. Diante disso, este estudo visa investigar a existência de softwares livres destinados à gestão de documentos, a fim de apresentar e discutir um modelo alternativo para essa situação de dependência econômica e tecnológica. Além disso, analisam-se os softwares livres sob a luz da teoria arquivística, considerando as características de tratamento documental preconizadas pela Arquivologia; isto é necessário para subsidiar o processo de avaliação do grau de viabilidade (inclusive características ergonômicas, tecnológicas e gerenciais) das ferramentas de software livre. Os resultados revelam, principalmente, um cenário onde se destacam iniciativas internacionais. Na esfera nacional, por outro lado, observam-se pouquíssimos projetos open source nesse domínio; contudo, parece haver uma tendência de crescimento de tais iniciativas no País.
\end{abstract}

\section{Palavras-Chave}

Arquivologia; Software; Gestão de Documentos; Software Livre 


\section{INTRODUÇÃO}

Observa-se, na literatura arquivística e na seara da Ciência da Informação, uma gama de estudos sobre a questão da automação em unidades e serviços de informação arquivística. A necessidade da implementação de sistemas informatizados de administração de documentos de arquivo parece não ser mais contestada, visto as características evidentes da contemporaneidade. De pleno acordo com Moreiro González:

El ordenador es eficaz en extremo para la gestión exacta y rápida de grandes magnitudes de información, así como para implantar nuevos sistemas de organización y gestión de la información, bases de datos y bases de conocimientos. Es el apoyo permanente del profesional para almacenar y recuperar la información. Ninguno de los procesos técnicos o profesionales pueden considerarse en la actualidad sin la participación intermediadora de las tecnologías automatizadas. (MOREIRO GONZÁLEZ, 2005, p. $50)$.

Diante dessa situação, várias pesquisas - algumas citadas ao longo deste artigo - têm sido desenvolvidas para avaliar, especificamente, programas informáticos de gerenciamento de documentação arquivística. Contudo, essas abordagens focam

\footnotetext{
${ }^{1}$ Parafraseando o autor: "O computador é eficaz ao extremo para a gestão exata e rápida de grandes magnitudes de informação, assim como para implantar novos sistemas de organização e gestão da informação, bases de dados e bases de conhecimentos. É o apoio permanente do profissional para armazenar e recuperar a informação. Nenhum dos processos técnicos e profissionais podem se sustentar na atualidade sem a estrutura proporcionada pelas tecnologias automatizadas".
}

soluções disponíveis, de uma forma geral, no mercado do software proprietário ${ }^{2}$. Desta forma, esta pesquisa objetivou estabelecer uma discussão sobre os sistemas de gestão arquivística baseados em software livre.

Com o objetivo específico de pesquisar, identificar e avaliar - de acordo com a teoria da Arquivologia - ferramentas de software livre para a gestão de documentos, esta investigação procura também abordar o modelo de desenvolvimento e utilização dessa categoria de software, buscando apresentar alternativas para a situação de dependência econômica e tecnológica imposta pela indústria do software proprietário.

Diante da observação de um contexto em que instituições arquivísticas e diversos setores de arquivos de empresas possuem consideráveis dificuldades financeiras, principalmente para a informatização de seus serviços de informação, o software livre pode se apresentar como uma solução para tal questão. Os custos para adoção e eventual suporte e manutenção de tais soluções podem ser muito mais baixos

\footnotetext{
2 Software proprietário é um programa desenvolvido por uma empresa comercial, que não disponibiliza o código fonte do seu produto (ou programa), o que impede o usuário de customizá-lo ou adequá-lo às suas necessidades de uma forma livre e autônoma. Isto ata o usuário à empresa que desenvolveu esse programa e às tecnologias e padrões utilizados por essa empresa para a construção desse software, o que implica, de forma decisiva, numa situação de dependência tecnológica e econômica.
} 
quando comparado aos softwares proprietários e suas onerosas licenças e royalties.

Quanto à questão de ordem tecnológica, deve-se refletir sobre a possibilidade de os usuários se tornarem reféns de tecnologias desenvolvidas por fornecedores únicos, tais como plataformas, padrões, formatos de arquivos, entre outros. Isso deve ser muito bem pensado quando se vai conceber um software de gestão arquivística, sobretudo quando se fala em documentos e preservação digital.

Além disso, considerando as recomendações elucidadas por órgãos competentes relacionados à gestão de arquivos, a exemplo do Conselho Nacional de Arquivos (CONARQ), que recomenda o desenvolvimento e a concepção de sistemas informatizados de gestão arquivística de documentos (SIGADs) baseados em padrões abertos (que são perfeitamente compatíveis com o modelo do software livre), este estudo enfatiza os requisitos arquivísticos preconizados pela teoria da Arquivologia que devem ser observados e contemplados no estabelecimento de ferramentas de software para a gestão arquivística de documentos, inclusive de formatos digitais. Esse corpus de técnicas é apresentado na quarta seção, após serem abordados os conceitos sobre o software livre e seu modelo de desenvolvimento e utilização. Este estudo procurou saber também qual o grau de viabilidade dessas ferramentas, anali- sando ainda aspectos ergonômicos e gerencias dos softwares livres.

\section{MÉTODO}

O método de execução do trabalho constitui-se das seguintes etapas:

a) Pesquisa bibliográfica sobre o tema de estudo: além de se estudar sobre o software, a indústria de software livre e a arquivística, consultou-se a literatura referente à automação de serviços de informação, tais como arquivos, bibliotecas, centros de documentação, museus, etc., com o objetivo de encontrar referências sobre sistemas informatizados livres de automação de arquivos. O que se pôde encontrar e consultar foram, principalmente, trabaIhos sobre softwares proprietários para automação desses serviços. Na esfera do free software, encontrou-se apenas trabaIhos sobre sistemas de gerenciamento de bibliotecas digitais, tais como o de Kuramoto (2005) Apesar de o foco dessas pesquisas não ser em gestão arquivística, elas serviram de referência para o desenvolvimento do presente estudo;

b) Pesquisa de informações e referências sobre softwares livres de gestão de documentos de arquivo: utilizou-se principalmente a Internet, objetivando-se fazer um levantamento em repositórios web de projetos de software livre, tais como as comunidades internacionais do Source Forge, Savannah, G Forge e Freshmeat. 
No âmbito nacional, pesquisou-se nas comunidades (incluindo-se as regionais) do Projeto Software Livre Brasil e do Código Livre $^{3}$. Para a pesquisa das referências de softwares, dentro de um universo de diversos projetos de vários outros domínios, foram utilizadas expressões de busca bem variadas, porém sempre relacionadas com a gestão de documentos. Assim, a título de ilustração, para a busca de referências nos repositórios internacionais foram utilizadas palavras-chave do tipo: "Document Management System", "Archiving", "Gestión Documentaire", "File Management", "Adminstrative Records", entre algumas outras pertinentes.

c) Análise das ferramentas de software livre: encontradas as referências de software, procedeu-se à realização de estudo sobre as mesmas, por meio de um instrumento de análise de softwares - o qual foi construído ressaltando principalmente os procedimentos arquivísticos relacionados nas próximas páginas desse artigo. Para o estabelecimento de tal instrumento analítico, procedeu-se a análise de alguns modelos de avaliação de softwares contidos em outros estudos, tais como: Côrte e outros (1999), Café e outros (2001), Pinto (1997), Flores e outros (2003), Kuramoto (2005), a partir dos quais

\footnotetext{
${ }^{3}$ Respectivamente: <http://sourceforge.net/>, $<$ http://savannah.gnu.org/>, <http://gforge.org/> , $<$ http://freshmeat.net/>, $<$ http://www.softwarelivre.org > .e $<$ http://www.codigolivre.com.br>
}

foram feitas várias adaptações e inseridos novos itens e aspectos concernentes à gestão arquivística. Este procedimento foi feito notadamente à luz da teoria da Arquivologia, mas foram observados também critérios ergonômicos ${ }^{4}$, tecnológicos e gerenciais ${ }^{5}$. Para a análise dos programas utilizou-se computador ${ }^{6}$ compatível com as resoluções requeridas pelos softwares, as quais não são exigentes; além do download dos programas, fez-se avaliação por meio de browser (ou navegador Internet) nos próprios sites de projetos de software, em seções de demonstração de funcionalidades. Devido ao espaço disponível neste artigo, não é possível apresentar a ferramenta de análise utilizada na avaliação (questionário sobre vários aspectos e funcionalidades dos softwares livres a gestão de arquivos).

De acordo com essa estratégia, a pesquisa foi elaborada no período de novembro de 2006 a abril de 2007. O presente trabalho não adotou um critério rígido para seleção dos softwares, assim, foi feito o levantamento de registros de forma aleatória obedecendo-se o cronograma da

\footnotetext{
${ }^{4}$ A Ergonomia, na esfera dos sistemas computacionais, preocupa-se essencialmente com o processo de engenharia dos softwares, onde se enfatiza a interface homem-máquina.

${ }^{5}$ Entende-se por características gerenciais aquelas de cunho genérico, presentes em todos os sistemas operacionais e aplicativos, tais como atividades de salvar, visualizar e imprimir registros, segurança de logs (senhas), auditoria, estatísticas sobre o próprio sistema, entre outros.

${ }^{6}$ Computador AMD Sempron ${ }^{\mathrm{TM}}$ Processor, 1.60 $\mathrm{GHz}, 448 \mathrm{MB}$ de RAM.
} 
pesquisa. Objetivou-se, principalmente, discutir a questão enunciada, analisandose alguma porção de programas informáticos livres que representassem os softwares livres de gestão de arquivos.

\section{O SOFTWARE LIVRE E SEU MODELO DE DESENVOLVIMENTO E USO ${ }^{7}$}

Nos anos recentes o movimento internacional pelo software livre tem alcançado crescente repercussão, impulsionado, inclusive, por iniciativas governamentais de vários países, entre eles o Brasil. O movimento fundamenta-se nos princípios de acesso à informação, liberdade de expressão e compartilhamento do conhecimento; é desenvolvido e disseminado de forma aberta, sem restrições de uso e modificação. Posição que segue opostamente à ideologia do universo proprietário (copyri$g h t$ ). Trata-se de uma opção que garante aos usuários a liberdade de executar, copiar, distribuir e aperfeiçoar o programa, de acordo com suas necessidades e interesses.

Free is being used as in "free spirit", "free thought", and perhaps even "free love". The software is unfettered by traditional intellectual property restrictions. More precisely, free software refers to the user's freedom to run, copy, distribute, study, change, and improve the software $^{8}$ (RUSOVAN et al. , 2005, p. 110).

\footnotetext{
${ }^{7}$ Para um referencial maior sobre o software ver, por exemplo, o artigo de Jambeiro e outros (2006).

"Parafraseando os autores: O termo "free" (livre) tem sido usado no sentido de liberdade de espírito, liberdade de pensamento e até no sentido de gran-
}

Conforme Raymond (2001), existem quatro liberdades no âmbito do software livre:

a) liberdade de executar o programa, para qualquer propósito;

b) liberdade de estudar como o programa funciona, e adaptá-lo às suas necessidades;

c) liberdade de redistribuir cópias de modo que você possa ajudar ao seu próximo;

d) liberdade de aperfeiçoar o programa e liberar os seus aperfeiçoamentos, de modo que toda a comunidade se beneficie;

De acordo com a Fundação Software Livre, um programa é software livre se os usuários têm todas essas liberdades. Portanto, os usuários são livres para redistribuir cópias, seja com ou sem modificações, seja de graça ou cobrando uma taxa pela distribuição, para qualquer parte ${ }^{9}$.

Ser livre significa, principalmente, que não se tem que pedir ou pagar pela permissão dessa liberdade. É importante, nesse sentido, não confundir "software livre" com "software grátis" porque a liberdade associada ao software livre de copiar, modificar e redistribuir independe de gratuidade $^{10}$. Existem programas que podem ser obtidos gratuitamente, mas que não podem ser modificados nem redistribuídos devido

de solidariedade. Esse software está desembaraçado de restrições tradicionais próprias do universo proprietário. Mais precisamente, a liberdade do software refere-se à possibilidade de o usuário utilizar, copiar, distribuir, estudar, trocar experiências e aperfeiçoar o programa".

${ }^{9}<$ http://www.gnu.org/philosophy/free-sw.pt.html>. Acesso em 10 mar. 2007.

${ }^{10} \mathrm{Em}$ inglês: free software versus free beer, onde free significa liberdade de expressão, e não gratuidade. 
à proteção do copyright, o que implica na impossibilidade de customização pelos usuários.

Por outro lado, o usuário pode pagar uma taxa para receber cópias de software livre, ou pode obtê-las sem custo algum, mas, independente de como se obteve a cópia, sempre deve haver a liberdade de copiar e modificar o software (livre), ou até mesmo vender cópias. O que regulamenta, de forma decisiva tais questões são as categorias de licença do software livre e do software de código aberto (open source), tais como a GNU GPL - General Public License, a GNU LGPL - Lesser General Public License, a DFSG - Debian Free Software Guidelines, a BSD - Berkeley Software Distribution, entre várias outras ${ }^{11}$.

Com relação às características de conveniência do uso do software livre, muitos estudiosos defendem sua adoção. Afirmam haver benefícios quando considerados, entre outros, aspectos, tais como: autonomia tecnológica, segurança, independência de fornecedores e compartilhamento do conhecimento.

Hexsel (2002, p.12) lista vários pontos quanto às vantagens e desvantagens do uso do software livre. Dentre as vantagens:

(1) custo social é baixo, (2) não se fica refém de tecnologia proprietária, (3) independência de fornece-

\footnotetext{
${ }^{11}$ Há uma relação de licenças em <http://www.gnu.org/licenses/license-list.html>. Acesso em: 10 mar. 2007.
}

dor único, (4) desembolso inicial próximo de zero, (5) não obsolescência do hardware, (6) robustez e segurança, (7) possibilidade de adequar aplicativos e redistribuir versão alterada, (8) suporte abundante e gratuito, e (9) sistemas e aplicativos geralmente muito configuráveis.

As desvantagens segundo o mesmo autor, seriam: "(1) interface de usuário não é uniforme nos aplicativos, (2) instalação e configuração podem ser difíceis, e (3) mão de obra escassa e/ou custosa para desenvolvimento e/ou suporte". (Hexsel, 2002, p.12)

Embora possa, eventualmente, haver alguma crítica à proposição de Hexsel, tais como: a discordância quanto à $1^{\text {a }}$ desvantagem (texto formulado em 2002) e a aparente incoerência entre os itens (8) das vantagens e (3) das desvantagens; é possível afirmar que, de um modo geral, ela está bastante razoável e condizente com vários estudos sobre o software livre.

O software livre é uma opção no sentido também da padronização, pois tem como diretriz a adoção de padrões abertos - plataformas de hardware, software, protocolos de comunicação, formatos, linguagens - o que propicia fácil portabilidade dos produtos e, portanto, maior poder de disseminação no mercado. Nesse sentido, quanto aos padrões e formatos abertos, pode-se dizer que a adoção de softwares livres está condizente com as resoluções e normas recomendadas pelo CONARQ e outros órgãos competentes em Arquivolo- 
gia. Portanto, é uma alternativa também para a preservação dos documentos e arquivos digitais, inclusive ${ }^{12}$.

No que concerne ao modelo de desenvolvimento da indústria do software livre, pode-se dizer que ele é produzido em contextos de comunidades de prática. No âmbito dessas comunidades, consolida-se o modelo de invenção coletiva, também conhecida pelo termo gift economy. Como afirmam Wenger e Snyder (2000) as comunidades se constituem como redes de conhecimento, onde seus agentes compartilham experiências e conhecimentos de forma criativa, com o objetivo de promover novas abordagens para resolução de problemas concretos.

Assim, observa-se que 0 caráter de alta customização presente no software livre representa uma importante alternativa para a construção de ferramentas cada vez mais robustas e eficientes. O software livre se constitui, portanto, numa metodologia para a automação de rotinas de gestão de informação arquivística, coerente com os princípios de livre acesso à informação e ao conhecimento produzido, princípios estes enfatizados pela chamada Sociedade da Informação.

\section{ADMINISTRAÇÃO DA INFORMAÇÃO ARQUIVÍSTICA}

Os arquivos podem ser definidos como "o conjunto de documentos que, independente da natureza ou do suporte, são reunidos por acumulação ao longo das atividades de pessoas físicas ou jurídicas, públicas ou privadas" (DTA, 1996, p.5). De acordo com Schellenberg (2006, p.41) "as características essenciais dos arquivos relacionam-se, pois, com as razões pelas quais os documentos vieram a existir [...]". Percebe-se assim que os documentos possuem um caráter orgânico, peculiar à organização que os criou, fato que os diferencia de outros tipos de documentos (bibliográficos, museológicos, etc.). Desta forma, os softwares analisados no escopo desta investigação correspondem ou devem focar a gestão de documentos de arquivo, o que é diferente de softwares voltados para automação de bibliotecas ou outros tipos de conteúdo.

Em arquivística define-se o ciclo vital dos documentos, o qual é dividido em três fases: 1) corrente, 2)intermediária e 3) permanente ${ }^{13}$. Trata-se de umas das principais características do tratamento documental arquivístico, que tem por finalidade racionalizar o fluxo dos documentos, integrando, de forma sistemática, todas as fases da gestão de documentos.

\footnotetext{
${ }^{13}$ Devido ao espaço não serão discutidos tais conceitos. Ver, por exemplo, a obra de PAES (2005).

${ }^{12}$ Nessa abordagem, ver, por exemplo, o trabalho de Sayão (2005).
} 
No âmbito dos valores e do ciclo de vida dos documentos existem as chamadas funções arquivísticas, que devem ser observadas de modo a envolver o conjunto dos princípios, métodos e operações concernentes ao tratamento arquivístico. Conforme Rosseau e Couture (1998, p. 265), há sete funções a considerar: produção, avaliação, aquisição, conservação, classificação, descrição e difusão dos arquivos ${ }^{14}$.

Dar-se-á destaque, aqui, à conservação ou preservação (num sentido mais amplo) dos arquivos. Quanto a isso, podese dizer que se trata de um ponto de maior destaque, visto que se tudo se perder não haverá arquivos a tratar e informação a difundir. Isto possui importância ainda maior quando se fala em documentação de cunho permanente. Uma política de preservação de registros deve destacar, além da metodologia consolidada de conservação de suportes físicos de informação, planos de ação para salvaguarda de dados e documentos digitais ${ }^{15}$. No contexto contemporâneo, em que são gerados, de forma substancial e ascendente, arquivos estruturados em dígitos, os chamados documentos eletrônicos, as organizações devem atentar para a conservação do seu estoque informacional digital, já que tal

\footnotetext{
${ }^{14}$ Não serão apresentadas essas definições, pela limitação deste espaço. Detalhes na referência.

${ }^{15}$ Com relação a metodologias de conservação e preservação de documentos tradicionais, ver, por exemplo, o capítulo 13 de Arquivos Modernos: princípios e técnicas (SCHELLENBERG, 2006).
}

ambiente é bastante volátil e suscetível a desgastes de ordem multifacetada.

Nesse sentido, com o objetivo de orientar a comunidade arquivística, a Organização das Nações Unidas para a Educação, Ciência e Cultura (UNESCO), o Conselho Internacional de Arquivos (ICA) e, no Brasil, o CONARQ, estabeleceram diretrizes para a preservação do patrimônio arquivístico digital, enfatizando a problemática a ser enfrentada para a consecução desse objetivo; no âmbito dessa questão, destaca-se como um dos principais requisitos a utilização de sistemas baseados em padrões e protocolos abertos, o que está em consonância com as plataformas de software livre e de código aberto, favorecendo a preservação digital, uma vez que há independência tecnológica quanto a padrões e formatos produzidos exclusivamente por players da indústria do software proprietário ${ }^{16}$. Além disso, para que a preservação digital aconteça de forma eficiente, faz-se necessário que o software de gerenciamento arquivístico possua módulos para suportar uma estrutura adequada de metadados de descrição de documentos. Isso é fundamental para a identificação do contexto dos arquivos digitais e sua conseqüente salvaguarda ${ }^{17}$. A iniciativa do

\footnotetext{
${ }^{16}$ Ver $<$ http://www.arquivonacional.gov.br/conarq/cam_tec _doc_ele/preservacao/cartapreservacao.asp $>$. $\overline{\mathrm{A}}$ cesso em 10 mar. 2007.

17 Para maiores informações sobre estruturas de metadados requeridos para a preservação digital
} 
e-ARQ ${ }^{18}$, do CONARQ, além de estabelecer requisitos para a concepção e avaliação de SIGADs, aponta ainda para o estabelecimento de critérios de metadados para auxiliar também o processo de preservação das características de fidedignidade e autenticidade dos documentos eletrônicos. Em sistemas híbridos de gestão de documentos (gerenciamento tanto de suportes tradicionais quanto de arquivos digitais), a preservação de metadados também deve ser garantida pelos softwares, além dos próprios documentos e arquivos eletrônicos.

Não é possível, por ora, discutir profundamente a totalidade da teoria relativa aos arquivos; o leque de conceitos supracitados deve ser considerado, portanto, como um referencial para análise dos programas livres de gerenciamento de arquivos.

\section{ANÁLISE DE SOFTWARES LIVRES DE GESTÃO DE ARQUIVOS}

Destacaram-se cinco ferramentas para o estudo, dentre a gama de produtos pesquisados. Devido ao espaço disponível

consultar, por exemplo, os estudos de Rondinelli (2002).

${ }^{18}$ No período de redação deste artigo ainda não havia sido lançado o documento final do e-ARQ. É uma iniciativa bastante importante para o desenvolvimento e análise de SIGADs. A iniciativa adota como referências a norma ISO 15.489, o modelo de requisitos funcionais da UE (MoReq) e as especificações de requisitos do DoD (EUA). Mais informações em:

<http://www.arquivonacional.gov.br/conarq/cam_tec _doc_ele/index.asp>. Acesso em 10 mar. 2007. para este artigo não é possível um grau de descrição mais detalhado dessas ferramentas, fazendo-se, então, uma abordagem mais geral, porém essencial e necessária para a compreensão das características desses produtos. Assim, entende-se que os softwares livres analisados representam a categoria de produtos desse domínio, pois foram encontradas outras iniciativas muito parecidas com as que a seguir serão apresentadas:

1) ARCHIVISTA Box ${ }^{19}$ - Este software livre é desenvolvido pela companhia alemã Archivista $\mathrm{GmbH}$. É uma ferramenta que permite a gestão de arquivos digitalizados, pois foca toda a cadeia de digitalização de documentos, desde a captura até o armazenamento e preservação dos arquivos digitais e conseqüente recuperação. Uma característica bastante importante neste programa é o fato de ele trabalhar apenas com formatos de padrões abertos tais como o Portable Document Format (PDF), o que, de acordo com a literatura especializada sobre preservação digital, é bastante importante para facilitar o acesso aos documentos durante longos períodos, evitando assim que os usuários fiquem à mercê de tecnologias proprietárias. Com relação aos aspectos ergonômicos e gerenciais, pode-se dizer que o programa parece ser eficiente e fácil de usar, possu-

\footnotetext{
${ }^{19}$ Sítio do projeto:<http://www.archivista.ch>. Acesso em 10 mar. 2007.
} 
indo também interfaces gráficas bastante intuitivas e simples. Possui seções específicas para descrição de documentos (apesar de não se observar que o programa comporta uma estrutura de metadados arquivísticos adequada na versão atual analisada), possuindo também mecanismos de busca variados. De uma forma geral, podese afirmar que o programa é razoável naquilo que se propõe a executar, apesar de não possuir alguns requisitos arquivísticos fundamentais enunciados nesta pesquisa, tais como, por exemplo: planos de classificação e tramitação eficientes e módulos de avaliação e destinação de arquivos. Atualmente está disponível apenas em alemão e inglês.

2) KNOWLEDGE TREE Document Management System ${ }^{20}$ - Muito mais abrangente sob a ótica da gestão de documentos que a ferramenta anterior, este software livre é uma iniciativa sul-africana, desenvolvido pela empresa JamWarehouse. Possuindo diversos modelos de licenciamento, sendo também licenciável sob a GNU GPL, o programa possui seu banco de dados em ambiente $M Y S Q L^{21}$ e funciona em vários sistemas operacionais (tais como MSWindows $₫$ e GNU/Linux), possuindo assim o status de software portável.

\footnotetext{
${ }^{20}$ Disponível em: <http://www.knowledgetree.com>. Acesso em 10 mar. 2007.

${ }^{21} \mathrm{O} M y S Q L$ é um sistema de gerenciamento de banco de dados (SGBD), que utiliza como interface a linguagem SQL (Structured Query Language Linguagem de Consulta Estruturada).
}

No que concerne às suas funcionalidades, o estudo da atual versão do software (3.4.5) permite afirmar que trata-se de um programa bem desenvolvido (inclusive ergonômica e tecnologicamente), aceitável para as rotinas de gestão de documentos. Sob o ponto de vista arquivístico pode-se dizer que agrega várias funções gerais (criação, indexação, armazenamento, resumos, recuperação de informações) presentes em outros programas. Mas algo que chama bastante atenção neste software é o fato de ele contemplar vários pontos relativos à tramitação de documentos, tais como metadados (apesar de a estrutura atual ainda não ser a ideal), controle de versões dos documentos e funcionalidades de workflow, que permite acompanhar o caminho do documento (isso na arquivística é bastante interessante porque ajuda a identificar o contexto dos documentos e suas inerentes particularidades, tais como informações sobre custódia.); nessa questão o software considera (e cita) o conceito de document's lifecycle (ciclo de vida do documento). Contudo, possui várias lacunas arquivísticas. O programa está disponível em várias línguas; algo que também chamou bastante atenção é o fato de se ter, no âmbito deste software, um projeto de tradução para língua portuguesa, a partir da colaboração de programadores simpatizantes com tal iniciativa. 
3) MAARCH Maerys Archives ${ }^{22}$ - Este software livre é uma iniciativa francesa. Foca o gerenciamento de documentos de arquivo, compreendendo módulos para muitas rotinas básicas, tais como: classificação, indexação e recuperação de registros. Do ponto de vista ergonômico do programa, incluindo-se os aspectos gerenciais, é possível afirmar que a atual segunda versão do sistema é aceitável, embora sejam necessários maiores aperfeiçoamentos como, por exemplo, na interface do programa e seu aspecto gráfico quando comparado aos outros softwares apresentados. Arquivisticamente, nota-se que o MARRCH não contempla completamente os requisitos elucidados pela teoria. Executa, assim como muitos outros, muitas funções de gestão de documentos, mas pode-se dizer que ainda é bastante incipiente quanto à arquivística. São pervcebidas várias falhas, tais como a inexistência de módulos para a integração das fases de gestão arquivística, trâmite, seções de empréstimo, controle e descrição eficientes. Atualmente o software está disponível nos idiomas inglês e francês.

4) OPENGED $^{23}$ - Outra iniciativa francesa, este software é desenvolvido pela NAOS Technologies, focando também o gerenciamento de documentos. Muito pa-

\footnotetext{
${ }^{22}$ Disponível em <http://www.maarch.org>. Acesso em 10 mar. 2007.

${ }^{23}$ Página website do projeto:

$<$ http://www.openged.com>. Acesso em 10 mar. 2007.
}

recido com o programa citado anteriormente (porém melhor), em termos de aspectos de interface, por exemplo, suas funcionalidades de administração de documentos são, da mesma forma, bastante elementares. Basicamente, faz o gerenciamento de processos e práticas de gestão de documentos comuns em outros softwares. Atualmente o software está disponível nos idiomas inglês e francês, mas há um projeto de tradução para a língua portuguesa.

5) OWL INTRANET ${ }^{24}$ - Trata-se de uma iniciativa estadunidense; está hospedada no repositório de projetos do Source Forge. É um software bem apresentável, parecendo ser bem desenvolvido para suas funções de gerenciamento de documentos de arquivo. Sob o ponto de vista ergonômico, principalmente, é bem elaborado, apresentando inclusive características de intuitividade, entre outros. Sobre a situação arquivística do programa, pode-se afirmar que realiza vários procedimentos de gerenciamento de arquivos, destacando-se um pouco (assim como o Knowledge Tree) entre os programas aqui analisados. Além de rotinas comuns, o software é capaz de suportar planos de classificação mais estruturados, possui módulos para o monitoramento de documentos e mecanismos mais desenvolvidos para definir acesso especial a seções restritas. Pôde-se per-

\footnotetext{
${ }^{24}$ Disponível em <http://www.owl.sourceforge.net>. Acesso em 10 mar. 2007.
} 
ceber também - a partir da análise da atual versão (0.91) - que as funções de pesquisa, localização e apresentação de registros são bem executadas, apesar de os módulos de pesquisa ainda não sustentarem o método booleano. Contudo, também possui lacunas no processo arquivístico, tais como a impossibilidade de tratar sistematicamente a seleção, a avaliação e a destinação dos documentos arquivísticos, não completando todos os estágios de gestão. Outro ponto negativo refere-se à inexistência de implementação de critérios de descrição arquivística para a identificação do contexto de produção dos documentos.

Todos os programas são acessíveis por navegador ou browser (web-based), possuindo estrutura Internet 'clienteservidor'.

É importante ressaltar que os programas supracitados são constantemente atualizados por novas versões lançadas por usuários e/ou desenvolvedores desses softwares. Assim, as considerações feitas sobre cada produto são aplicáveis a esses estágios atuais de desenvolvimento e, certamente, serão desatualizadas por novas versões lançadas numa data relativamente próxima. Esse caráter altamente dinâmico confere excelentes perspectivas de aprimoramento das ferramentas, pela característica do modelo colaborativo dessas comunidades de prática, de forma bastante eco- nômica e livre da "camisa de força" imposta pela indústria do software proprietário.

Todos os softwares identificados são iniciativas internacionais. Todas elas estão em sua maioria, como visto anteriormente, apenas em língua estrangeira. Isso, contudo, não se traduz em problemática, pois o processo de tradução de softwares não é complexo e é também feito por colabores dos projetos, podendo ser realizado dentro da própria dinâmica da comunidade de desenvolvimento.

$\mathrm{Na}$ esfera nacional de comunidades de prática de desenvolvimento de software livre, as quais são mencionadas na seção metodológica deste artigo, não foram localizados iniciativas ou projetos relacionados à gestão arquivística de documentos. Isto talvez possa ser explicado pelo fato de tais comunidades brasileiras serem muito mais novas (em termo de idade de fundação) que comunidades estadunidenses como, por exemplo, a Source Forge, fundada em 1999.

Contudo, no Brasil, esta pesquisa percebeu a existência de algumas iniciativas de desenvolvimento de softwares livres de gestão de informação documental (inclusive de gestão arquivística). São iniciativas espalhadas, isto é, não estão agregadas em um dado website de hospedagem, como uma comunidade de desenvolvimento. Nesse sentido, tem-se o PSL - Ciência da Informação (Projeto de Software Livre 
em Ciência da Informação), que objetiva customizar e traduzir soluções de software livre voltadas para a Ciência da Informação; esta iniciativa visa contemplar também o estabelecimento de ferramentas livres para gestão arquivística de documentos (LUZ, 2005).

Outra iniciativa é o Projeto Arquivo Livre ${ }^{25}$, o qual também objetiva, de forma mais específica, o estabelecimento de uma solução livre para gestão arquivística de documentos, a partir dos princípios teóricos arquivísticos. Além dessas atitudes, apresentam-se também as próprias iniciativas de tradução de alguns dos softwares avaliados, como visto, a partir do interesse de usuários e/ou programadores colaboradores. Esse quadro parece refletir a busca por alternativas de soluções de software mais econômicas, independente de tecnologias proprietárias e, conseqüentemente, mais eficientes, inclusive sob a ótica da gestão arquivística.

\section{CONSIDERAÇÕES FINAIS}

Como foram apresentadas ao longo deste trabalho, as iniciativas de projetos de software livre na área da gestão de documentos de arquivo são predominantemente estrangeiras, contrapondo-se à realidade nacional, que apresenta, atualmente, pouquíssimas iniciativas de desenvolvimento

\footnotetext{
${ }^{25}$ Disponível em:

<http://twiki.softwarelivre.org/bin/view/ArquivoLivre/ WebHome> . Acesso em 10 mar. 2007.
}

de soluções ou de tradução de softwares livres produzidos internacionalmente nas comunidades de prática. Entretanto, parece correto afirmar que há perspectivas para o crescimento dessas iniciativas.

As conclusões referentes à análise dos softwares são as seguintes:

\section{1. quanto às características ergo-} nômicas: observa-se que todos os softwares possuem, de uma forma geral, níveis aceitáveis de qualidade; em outras palavras, são bem desenvolvidos quanto aos critérios ergonômicos da engenharia do software; ao contrário dos que muitos podem pensar sobre os softwares livres, as interfaces gráficas são bem construídas e intuitivas; assim, parecem ser altamente compatíveis com os programas tradicionais;

\section{2. quanto às características arqui-} vísticas: todos eles apresentam baixo desempenho, o que é natural, seguindo-se a tendência de uma grande quantidade de softwares proprietários desse domínio, estudados e apresentados por outros autores. É exatamente nesta questão que os desenvolvedores e colaboradores devem focar para a consolidação de ferramentas eficientes e robustas de gestão arquivística. Está aqui a importância da utilização de software livre, já que a cooperação entre as comunidades de desenvolvedores $\mathrm{e}$ usuários - proporcionada pela troca de experiências -, principalmente, pode pos- 
sibilitar a construção e o aperfeiçoamento constante das ferramentas. Não é preciso reinventar a roda; a partir de experiências diversas podem ser retificados problemas, desenvolvidos novos módulos de atividades e rotinas, compartilhadas soluções. No âmbito do software proprietário (sob o copyright), há grandes restrições para os desenvolvedores e usuários, o que impossibilita desfrutar da liberdade e solidariedade proporcionadas pelo software livre. Observa-se, de acordo com os estudos que embasaram esta investigação, que os próprios softwares proprietários, em sua vasta maioria, não são eficientes arquivisticamente; isso resulta na ilusão de muitas organizações procurarem por ferramentas "ideais", sem, contudo, realmente encontrá-las no mercado, na maioria das vezes pagando por licenças altamente onerosas de programas incompletos e, portanto, ineficientes. Os softwares produzidos in house (isto é, desenvolvidos pela própria equipe de TI de uma determinada empresa) correm o perigo de serem construídos sem knowhow arquivístico, o que, certamente, poderá acarretar prejuízos no futuro. Tem-se, assim, a alternativa do software livre, no sentido de serem construídas soluções robustas e eficazes para o gerenciamento arquivístico (sendo observados os requisitos teóricos), de uma forma solidária, muito mais econômica, de acordo com padrões abertos elucidados pela competência ar- quivística e independente de tecnologias únicas;

\section{3. quanto aos critérios gerenciais:} pôde-se perceber um número reduzido de falhas e, como ocorre na parte ergonômica, são também bem observados e razoavelmente atendidos pelos programas analisados, sendo compatíveis com a tradição.

Em razão disso, é possível afirmar que o grau de viabilidade atual desses softwares livres, no atual estágio de suas versões, ainda é insustentável arquivisticamente, apesar de apresentarem excelentes características ergonômicas e gerenciais, assim como acontece em boa parte dos produtos lançados pela indústria do software proprietário. Contudo, com o modelo de desenvolvimento do software livre, parece haver excelentes perspectivas de aprimoramento constante dessas ferramentas e construção de ferramentas ideais (e contemplando padrões abertos) de gestão arquivística de documentos. Esta pesquisa sugere que $o$ assunto seja mais discutido na comunidade acadêmica e, notadamente, em grupos de programadores e usuários arquivistas, a fim de serem envidados esforços para a consecução, num futuro próximo, de ferramentas de gestão arquivística mais econômicas, robustas, eficientes e eficazes. 


\section{REFERÊNCIAS}

\section{ASSOCIAÇÃO DOS ARQUIVISTAS}

BRASILEIROS. Núcleo Regional de São

Paulo. Dicionário brasileiro de terminologia arquivística: contribuição para o estabelecimento de uma terminologia arquivística em língua portuguesa. São Paulo:

CENADEM, 1996.

CAFÉ, L.; SANTOS, C. dos; MACEDO, F. Proposta de um método para escolha de software de automação de bibliotecas. Ci. Inf., Brasília, v. 30, n. 2, p. 70-79, ago. 2001.

CÔRTE, A. R. et al. Automação de bibliotecas e centros de documentação: o processo de avaliação e seleção de softwares. Ci. Inf., Brasília, v. 28, n. 3, p. 241-256, dez. 1999.

FLORES, D. et al. Análise de produtos para gerenciamento eletrônico de documentos. CINFORM, 4. Salvador, 2003. Anais... Salvador: UFBA, 2003.

GONZÁLEZ, J. A. M. Conceptos introductorios al estudio de la información documental. Salvador: EDUFBA; Lima: Pontificia Universidad Católica del Peru, 2005.

HEXSEL, R. A. Propostas de ações de governo para incentivar o uso do software livre. Curitiba: UFPR, 2002.

JAMBEIRO, O.; BORGES, J.; SANTOS, J. $T$. Infra-estrutura da Sociedade da Informação: a indústria de software em Salvador - BA. DataGramaZero, Rio de Janeiro, n.1, v.7, fev. 2006.

KURAMOTO, H. Ferramentas de software livre para bibliotecas digitais. In: MARCONDES, Carlos Henrique et al. Bibliotecas digitais: saberes e práticas. Salvador: EDUFBA; Brasília: IBICT, 2005, p. 147-164.

LUZ, A. R. PSL - Ciência da Informação. In: CONGRESSO DE ARQUIVOLOGIA DO MERCOSUL, 6, 2005, Campos do Jordão.
Arquivos: O Saber e o Fazer. Campos do Jordão: Arq-SP, 2005. v. 1, CD-ROM.

PAES, M. L. Arquivo: Teoria e Prática. Rio de Janeiro: FGV, 2005.

PINTO, L. C. C. Análise, seleção e aquisição de software/hardware para sistema de informação. Ci. Inf., v. 26, n. 1, jan. 1997.

RAYMOND, E. S. The cathedral and the bazaar: Musings on Linux and open source by an accidental revolutionary. Sebastopol: O'Reilly, 2001.

RONDINELLI, R. C. Gerenciamento arquivístico de documentos eletrônicos. Rio de Janeiro: Editora FGV, 2002.

ROUSSEAU, J.; COUTURE, C. Os fundamentos da disciplina arquivística. Lisboa: D. Quixote, 1998.

RUSOVAN, S.; LAWFORD M.; PARNAS, D. L. Open souce software development: future or fad? In: FELLER, J. et al. Perspectives on free end open source software. Cambridge: The MIT Press, 2005.

SAYÃO, L. F. Preservação digital no contexto das bibliotecas digitais: uma breve introdução. In: MARCONDES, C. H. et al. Bibliotecas digitais: saberes e práticas. Salvador: EDUFBA; Brasília: IBICT, 2005.

SCHELLENBERG, T. R. Arquivos Modernos: princípios e técnicas. Rio de Janeiro: FGV, 2006.

WENGER, E., SNYDER, A. W. Jr. Communities of practice: the organizational frontier. Harvard Business Review, v.75, n.1, Dec./Jan., 2000. 


\section{João Tiago Jesus dos Santos \\ Graduado em Arquivologia pelo Instituto de \\ Ciência da Informação (UFBA) joaotiago1@yahoo.com.br}

\section{Lídia Maria Batista Brandão Toutain}

Doutora em filosofia pela Universidad Leon

(Espanha).

Diretora e professora do Instituto de Ciência da

Informação / UFBA.

lbrandao@ufba.br

\section{Title}

Archive's information units automation: the free software alternative model

\begin{abstract}
The article establishes a debate concerning software solutions applied to archive's document management. Previous studies reveal a considerable number of application's options in this category; however, these studies had emphasized with major predominance the unfree alternatives applications. In this sense, this study aims to investigate the existence of free software applications for the document management process, in order to present and to discuss an alternative model to overcome the economic and technological dependence. Moreover, free software solutions are analyzed under the light of the archive's theory, considering the characteristics of the documentary treatment proclaimed by the information storage; which is necessary to support the evaluation process and also to analyze the degree of implementation viability (including ergonomic, technological and also administrative characteristics). The results reveal that in this field international initiatives are standing out. On the other hand, in the national sphere (Brazil) very few open-source projects are observed in this domain; however, it seems to have a growing trend of such initiatives in the Country.
\end{abstract}

\section{Título}

Automatización de unidades de información de archivos: el modelo alternativo de software libre

\section{Resumen}

El artículo establece una discusión en el ámbito de los softwares de gestión de documentos de archivo. Los estudios previos revelan una cantidad considerable de productos de esta categoría; sin embargo, el universo comtemplado en estos análisis es predominantemente de software de propiedad. Frente a esto, este estudio tiene como objetivo investigar la existencia de softwares libres destinados a la gestión de documentos, con el fin de presentar y discutir un modelo alternativo para esta situación de dependencia económica y tecnológica. Por otra parte, se analizan los softwares libres bajo la luz de la teoría archivística, considerando las características del tratamiento documental procedentes de la Archivística; lo cual es necesario para subvencionar el proceso de evaluación de los grados de viabilidad (características ergonómicas, tecnológicas y también gerenciales) de las herramientas de software libre. Los resultados revelan, principalmente, un escenario donde destacan las iniciativas internacionales. En la esfera nacional, por otra parte, se observan muy pocos proyectos de "open source" o fuente abierta en este ámbito; sin embargo, parece que hay una tendencia al crecimiento de tales iniciativas en el País.

\section{Palabras Clave}

Archivística; Software; Gestión de Documentos; Software Libre.

Recebido em: 13.09.2007

Aceito em: 23.10.2007

\section{Keywords}

Archive Science, Software, Document Management, Free Software. 